\title{
Marcadores de gravedad en la pancreatitis aguda
}

Editorial:

Autor: Folch-Puy, Emma

El cambio más significativo en el curso clínico de la pancrea-titis aguda en la última década ha sido la disminución de la mortalidad global por esta enfermedad, que actualmente se cifra en un 10-20\% para los casos graves. Esta mejora se debe en gran parte al avance en las nuevas tecnologías y técnicas de soporte vital y a un mejor conocimiento de la fisiopatología de la pancreatitis. Aun así, todavía es muy necesario el desarrollo de nuevos tratamientos específicos que permitan modular de manera más eficaz el curso de la enfermedad.

La pancreatitis aguda es un proceso inflamatorio agudo del páncreas, que se manifiesta clínicamente por intensos dolores abdominales, acompañados de fiebre, vómitos, taquicardia, leucocitosis y aumento de las enzimas pancreáticas en sangre y/o orina. En la mayoría de los pacientes el proceso de la pancreatitis es leve y se resuelve bien con medidas de soporte nutricional y tratamiento con analgésicos. Sin embargo, un $25 \%$ desarrolla una forma grave, que cursa con complicaciones sistémicas. Cabe destacar que la mortalidad en esta enfermedad no está relacionada con la inflamación pancreática per se, sino con el síndrome de respuesta inflamatoria sistémica, proceso que cursa con un desarrollo similar al desencadenado como consecuencia de un traumatismo o sepsis.

El inicio de la pancreatitis aguda se caracteriza por la activación prematura de los cimógenos pancreáticos, lo que da lugar a un proceso de autodigestión del propio páncreas, con la consiguiente respuesta inflamatoria local provocada por la producción de citocinas por parte de las células acinares. A partir de este punto la pancreatitis puede evolucionar como un proceso leve y autolimitado, o bien progresar hacia una forma grave y culminar en una respuesta inflamatoria sistémica descontrolada. Por ello, desde el punto de vista clínico, es de vital importancia disponer de un sistema temprano de predicción del curso de la pancreatitis aguda. Con esta finalidad, a lo largo de los años se han ido definiendo numerosos parámetros de estimación de la gravedad, entre ellos sistemas de puntuación fisiológico-clínicos como el índice APACHE II (Acute Phisiology and Cronic Health Evaluation Scoring System), los criterios de Ranson y los de Glasgow-Imrie. La técnica de imagen más comúnmente utilizada es la tomografía computarizada, útil para evaluar las complicaciones locales de una pancreatitis aguda, pero no en órganos distantes. En cuanto a los marcadores bioquímicos, en los casos graves se han observado elevaciones importantes de varios de ellos, como la proteína C reactiva (PCR), el péptido activador del tripsinógeno o la elastasa polimorfonuclear. No obstante, ninguno cumple con los requisitos de especificidad, reproducibilidad, consenso y bajo coste deseables para su aplicabilidad clínica en la práctica habitual. 
En los últimos años se han propuesto las concentraciones séricas de ciertas citocinas como indicadores pronósticos de gravedad de la pancreatitis, al estar estrechamente relacionadas con el desarrollo del síndrome de respuesta inflamatoria sistémica. Estas moléculas polipeptídicas cobraron protagonismo cuando, en 1988, Rinderknecht describió por vez primera su papel en la fisiopatología de la pancreatitis aguda, que hasta aquel momento había estado centrado exclusivamente en las hidrolasas pancreáticas. La producción de citocinas es una de las señales generadas por el tejido pancreático dañado en las etapas iniciales de la enfermedad y contribuye a la selección de células inflamatorias hacia el páncreas. En ocasiones estas citocinas alcanzan concentraciones plasmáticas suficientes para inducir efectos en órganos distantes. Buena prueba de ello es la gran cantidad de trabajos que observan una relación entre los valores en suero de citocinas y la gravedad de la pancreatitis.

De entre estos mediadores, la interleucina (IL) 6 se considera el marcador temprano más fiable para la predicción de la gravedad de la pancreatitis aguda. Esta proteína es principalmente secretada por los macrófagos en respuesta a la lesión tisular y es el mediador principal en la síntesis de proteínas de fase aguda como el fibrinógeno o la PCR. La capacidad de las concentraciones séricas de la IL-6 para distinguir entre casos graves y leves de pancreatitis aguda se ha comparado con la de la PCR, e incluso se ha observado que los valores de aquélla son superiores en el momento de la admisión del paciente. El factor de necrosis tumoral alfa (TNF-*), que es uno de los mediadores iniciales del proceso inflamatorio, actúa como inductor de muchos de los procesos que confluirán en el cuadro de insuficiencia multisistémica. No obstante, su papel como marcador de gravedad en la pancreatitis aguda resulta poco claro, ya que, si bien en algunos casos sus valores séricos en pacientes con enfermedad grave se encuentran claramente aumentados, en otros sus concentraciones no aumentan ${ }^{9}$, mientras sí lo hacen otras citocinas como la IL-6 o la IL-8. Esto podría explicarse por su corta vida media en suero o por la dificultad que tienen algunos métodos de detección de esta citocina, al verse afectados por la presencia de proteínas que se unen al TNF-*, particularmente su propio receptor soluble (sTNFR). De hecho, la elevación de las concentraciones séricas de sTNFR predice el desarrollo de insuficiencia multisistémica, aun cuando el TNF-* se encuentra por debajo de las concentraciones detectables ${ }^{10}$. Al unirse al TNF-*, el sTNFR parece atenuar los efectos de la citocina proinflamatoria, por lo que puede considerarse una citocina antiinflamatoria. Otra de las proteínas moduladoras es el receptor antagonista de la IL-1 (IL-1Ra), que, al igual que el sTNFR, tiene un carácter antiinflamatorio y se considera un marcador de gravedad más fiable que su propia citocina.

De forma paralela a la liberación de citocinas proinflamatorias se produce un aumento de las antiinflamatorias: sTNFR, IL-1Ra y también la IL-10. Esta última modula una respuesta inflamatoria excesiva inhibiendo la producción de IL-1, IL-6, IL-8 y TNF-*. Por último, una citocina proinflamatoria recientemente descrita es la IL-18, conocida también como factor inductor de interferón gamma. La IL-18 es liberada por macrófagos y se ha relacionado con la respuesta inmunitaria tipo $\mathrm{T}$ helper-1. En el contexto de la pancreatitis aguda se ha observado una relación entre sus concentraciones séricas y el desarrollo de complicaciones locales y sistémicas en el curso de la enfermedad. 
Además de la producción de citocinas, la respuesta inflamatoria se caracteriza por una serie de cambios estructurales en la vasculatura que terminan con la migración y extravasación de los leucocitos al órgano dañado. Este proceso requiere la interacción del leucocito y la célula endotelial a través de las moléculas de adherencia. La forma soluble de la molécula de adherencia intercelular-1 (sICAM-1) es un marcador de activación leucocitaria que refleja la gravedad en las fases tempranas de la pancreatitis.

Más allá de diferenciar entre las pancreatitis leves y graves, sería deseable disponer de marcadores que puedan relacionarse con la disfunción de determinados órganos distantes. En este sentido, se sabe que el primer signo de disfunción multiorgánica en la pancreatitis aguda es la alteración de la función pulmonar, que puede variar desde una hipoxemia leve hasta el desarrollo de síndrome de distrés respiratorio del adulto. La lesión pulmonar se caracteriza por el aumento de la permeabilidad microvascular, la liberación de mediadores y la activación y la selección de neutrófilos en el compartimiento alveolar intersticial. Los pulmones devienen edematosos, hemorrágicos y congestionados, lo que da lugar al colapso de las vías aéreas, con una disminución de la distensibilidad pulmonar e insuficiencia respiratoria. Otros órganos afectados por una excesiva respuesta inflamatoria pancreática son el riñón y el hígado. La insuficiencia renal aguda en el curso de la pancreatitis aguda tiene una incidencia baja, pero, cuando aparece, se asocia a un mal pronóstico. Los 2 factores más importantes que contribuyen a la insuficiencia renal aguda son la hipovolemia y la hipotensión ${ }^{14}$. La insuficiencia hepática es menos frecuente que la pulmonar o la renal en la pancreatitis aguda. Aun así, un gran número de estudios clínicos describen que, aunque la lesión hepática aparece tan sólo en alrededor de un $5 \%$ de los casos, invariablemente lleva a la muerte. Los principales cambios histopatológicos en el hígado son la necrosis y la degeneración de los hepatocitos, así como la colangitis aguda causada por piedras ampulares.

En este ámbito, el estudio de Martín Alonso et al. publicado en el presente número de Medicina Clínica se sitúa en el contexto de predecir qué pacientes con pancreatitis desarrollarán afectación sistémica de pulmón, riñón o hígado. Los autores determinan, en 34 pacientes diagnosticados de pancreatitis aguda, las concentraciones séricas de una serie de parámetros inmunológicos (sTNFR e IL-1Ra como mediadores antiinflamatorios, e IL-6, IL-6R, IL-18 e ICAM-1 como proinflamatorios) en relación con parámetros de disfunción de los citados órganos. Se proponen como marcadores de lesión hepática el STNFR, IL-18, ICAM-1 e IL-6; como marcadores de disfunción renal, STNFR, ICAM-1 e IL-1Ra, y los mismos parámetros, además de la IL-6, para la disfunción pulmonar asociada a la pancreatitis. Teniendo en cuenta la dificultad que entraña predecir el curso de la pancreatitis aguda, sobre todo cuando la evaluación clínica se lleva a cabo en el momento del ingreso en el centro hospitalario, este trabajo es un punto de partida en la línea de disponer de marcadores que permitan identificar de una manera temprana qué órganos empezarán a verse afectados. Estas investigaciones han de permitir implementar estrategias terapéuticas más específicas para el tratamiento de esta enfermedad. 